\title{
Parametric study on the stiffness and energy absorption capacity of composite space truss
}

\author{
P. Sangeetha* \\ Department of Civil Engineering, SSN College of Engineering, Chennai, India
}

\section{A R T I C LE IN F O}

\section{Article history:}

Received 2 May 2017

Received in revised form

25 July 2017

Accepted 25 July 2017

\section{Keywords:}

Composite space truss

Energy absorption

Stiffness

ABAQUS

\section{Introduction}

Space truss is a three dimensional structure used to cover large area with or without intermediate support. The major problem of the space truss was the failure of the top chord members, which can be overcome by placing concrete slab along with shear connector over the space truss that act as composite space truss. The composite space truss can be used as floor system in the multi-storey and industrial building for rapid construction.

Mezzina et al. (1975) have presented two methods of analysis for prediction of the theoretical behaviour of the space truss. The method explains the step by step approach of the tension members to study it's the elastic and plastic behaviour. The yield line approach was also adopted to study the behaviour of the tension members. Both the theoretical analysis gives the collapse loads.

Elsheikh and McConnel (1993) have done experimental study on the space truss with over strengthened top chord member and concrete slab over the space truss to overcome the buckling of the critical top chord member and concluded that composite space truss performed better than the over strengthened top chord member.

Elsheikh (1998) has designed and optimized the double layer space truss and fitted the force limiting devices in the critical compression member and observed that the ductility and load carrying

\footnotetext{
* Corresponding Author.

Email Address: sangeethap@ssn.edu.in

https://doi.org/10.21833/ijaas.2017.09.001

2313-626X/C 2017 The Authors. Published by IASE.

This is an open access article under the CC BY-NC-ND license

(http://creativecommons.org/licenses/by-nc-nd/4.0/)
}

capacity were improved. The force limiting devices were more costly, so it was limited to use in the one or few members of the space structures. Lakshmikandhan et al. (2010) have carried out a parametric study on the behaviour of composite space structures using ANSYS and concluded that top concrete slab enhanced the strength of the top chord members and also increased the strength and stiffness of the system. Sangeetha and Senthil (2017) discussed the study on the ultimate load carrying capacity on the composite space truss with proper shear connector and concluded that the composite space truss with steel flat and bolts as shear connectors enhances the composite action. This paper emphasise the parametric study on the energy absorption, stiffness and ductility factor for varying slab thickness, module size and concrete strength of composite space truss analysed using ABAQUS.

\section{Analysis of composite space truss}

The composite space truss of $4 \mathrm{~m} \times 4 \mathrm{~m}$ and $9 \mathrm{~m} \times$ $9 \mathrm{~m}$ space truss were taken from the published experimental results were analysed. The parameters varied in their model to analysis using ABAQUS are slab thicknesses $(50 \mathrm{~mm}, 80 \mathrm{~mm}, 100 \mathrm{~mm}$ and 125 $\mathrm{mm}$ ), grade of the concrete (M25, M30 and M35) and the size of the space truss module $(800 \mathrm{~mm} \times 800$ $\mathrm{mm}, 1000 \mathrm{~mm} \times 1000 \mathrm{~mm}$ and $1333.3 \mathrm{~mm} \times 1333.3$ $\mathrm{mm})$. The steel space truss was modelled using Truss Element (T3D2) and concrete slab using Solid Element (C3D8) from element library of ABAQUS. The details of the elements are shown in Fig. 1 and the layouts of the space truss are shown in Fig. 2. Table 1 gives material property of steel and concrete used as input in analysis. 
Table 1: Material properties of steel and concrete

\begin{tabular}{cccc}
\hline So & Material Property & Steel & Concrete \\
\hline 1 & Young's modulus N/mm & $2 \times 10^{5}$ & $5000 \sqrt{\mathrm{f}_{\mathrm{ck}}}$ \\
2 & Poisson's ratio & 0.3 & 0.15 \\
3 & Density $\mathrm{kg} / \mathrm{m}^{3}$ & 7850 & 2500 \\
\hline & & &
\end{tabular}

Fig. 1: Truss and solid element
The non-linear analysis of the composite space truss was done using ABAQUS. Figs. 3 and 4 show the mesh model and deformed shape of the composite space truss of size $4 \mathrm{~m} \times 4 \mathrm{~m}$ and $9 \mathrm{~m} \times 9$ m.

The composite space truss model was restrained at four corner node of the bottom layer and subjected to the concentrated load at all intermediate node of top layer $(4 \mathrm{~m} \times 4 \mathrm{~m})$ and at intermediate node of the top layer $(9 \mathrm{~m} \times 9 \mathrm{~m})$.
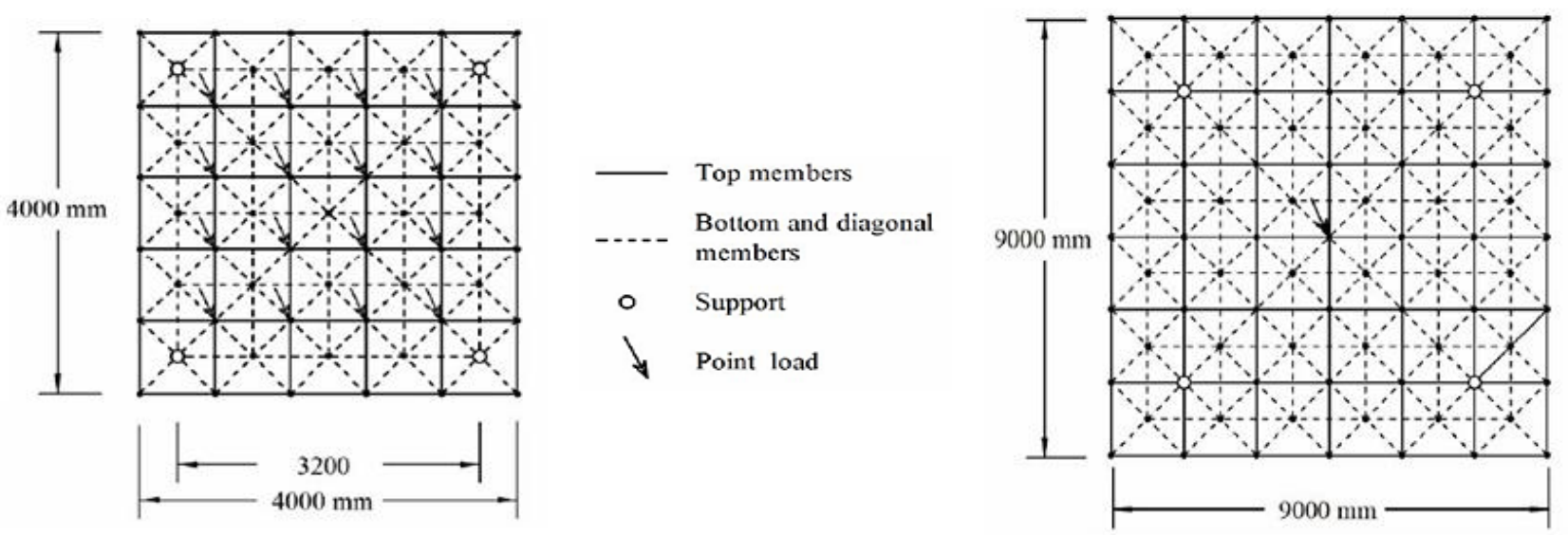

Fig. 2: Layout of the space truss
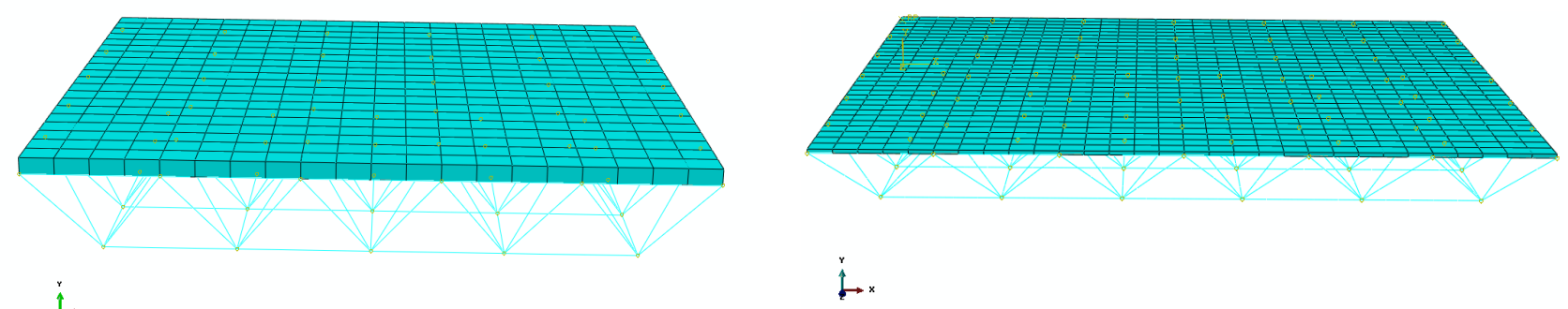

Fig. 3: Mesh model of $4 \mathrm{~m} \times 4 \mathrm{~m}$ and $9 \mathrm{~m} \times 9 \mathrm{~m}$ space truss
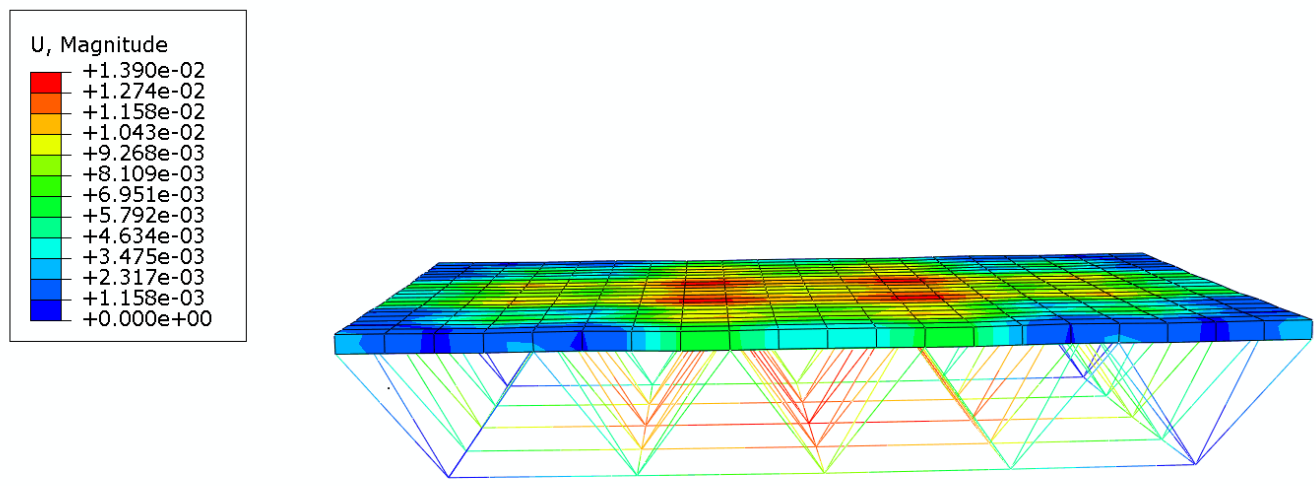

$\stackrel{\mathrm{I}}{\longrightarrow}$

ODB: elsheikcomnon50mm.odb Abaqus/Standard 6.14-1 Tue Jul 25 09:42:20 India Standard Time 2017

Step: Step-10

Increment 1 : Step Time $=1.000$

Primary Var: U, Magnitude

Deformed Var: $U$ Deformation Scale Factor: $+1.000 e+00$ 

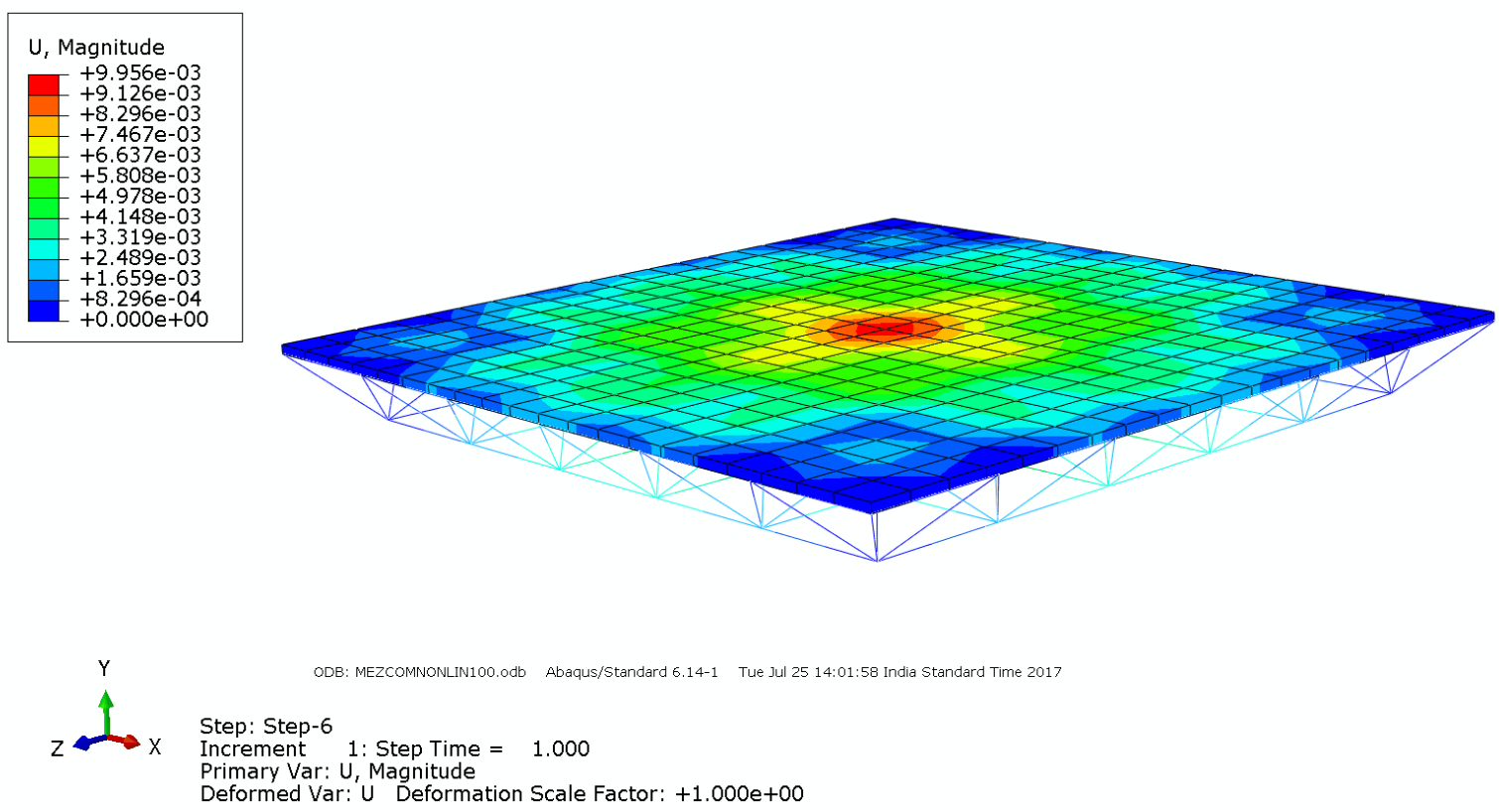

Fig. 4: Deformed shapes of $4 \mathrm{~m} \times 4 \mathrm{~m}$ and $9 \mathrm{~m} \times 9 \mathrm{~m}$ space truss

\section{Result and discussion}

Ductility and energy absorption capacity are more important for structures located in seismic areas. Ductility is defined as the ability of structure to deform plastically under load without any failure. The ductility factor of the space truss is defined as the ratio of the deflection at failure load to the deflection at the yield load of the extreme fibre in the compression region.

The yield deflection from the load - deflection plots are obtained by taking offset from the value of $0.2 \%$ as proof strain. Table 2 shows the calculated analytical values of energy absorption of the composite space truss having different module sizes. The ductility factor of the two different composite space truss are tabulated in Tables 3 and 4, indicates that composite space truss of $4 \mathrm{~m} \times 4 \mathrm{~m}$ exhibited greater values than $9 \mathrm{~m} \times 9 \mathrm{~m}$ truss.

The energy absorption is the work done by the external load up to the failure of the specimen. The area under the load-deflection diagram provides details of the energy absorption by the structure under loading. Tables 3 and 4 show the calculated analytical values of energy absorption of the composite space truss. The results show energy absorption capacity as the highest for the composite space truss with the lower thickness of the concrete slab. The mean energy absorption of $4 \mathrm{~m} \times 4 \mathrm{~m}$ is more than double that of $9 \mathrm{~m} \times 9 \mathrm{~m}$. A comparison of the energy absorption capacity of all types of composite space truss is shown in Fig. 5. This clearly shows the energy absorption capacity of $50 \mathrm{~mm}$ slab thickness as considerably greater than the $125 \mathrm{~mm}$.

Table 2: Analytical results of the composite space truss for varying module size

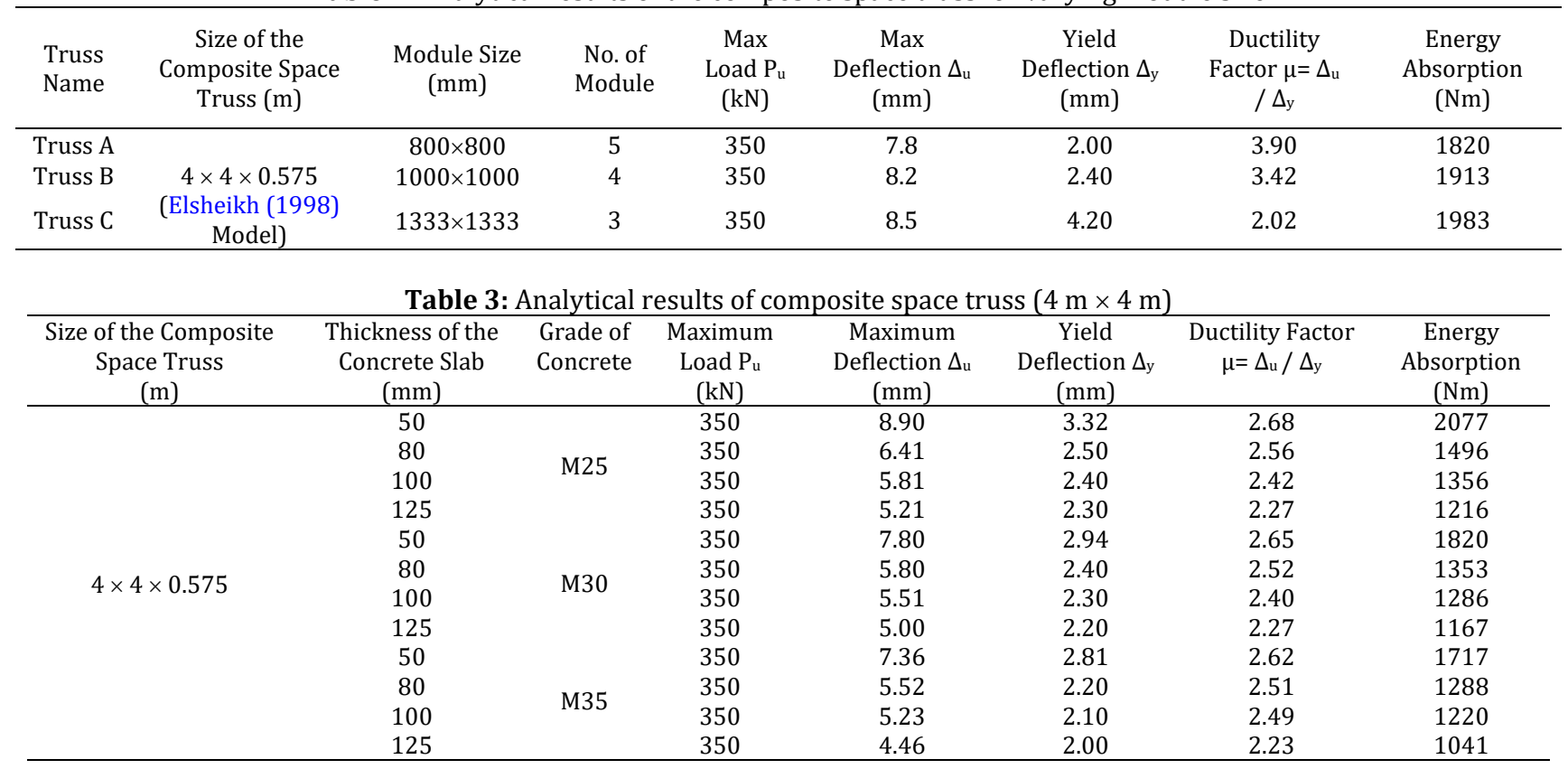


Table 4: Analytical results of composite space truss $(9 \mathrm{~m} \times 9 \mathrm{~m})$

\begin{tabular}{|c|c|c|c|c|c|c|c|}
\hline $\begin{array}{c}\text { Size of the } \\
\text { Composite Space } \\
\text { Truss (m) }\end{array}$ & $\begin{array}{l}\text { Thickness of the } \\
\text { Concrete Slab } \\
(\mathrm{mm})\end{array}$ & $\begin{array}{l}\text { Grade of } \\
\text { Concrete }\end{array}$ & $\begin{array}{c}\text { Maximum } \\
\text { Load } P_{u}(k N)\end{array}$ & $\begin{array}{l}\text { Maximum } \\
\text { Deflection } \Delta_{\mathrm{u}} \\
(\mathrm{mm})\end{array}$ & $\begin{array}{c}\text { Yield } \\
\text { Deflection } \Delta_{\mathrm{y}} \\
(\mathrm{mm})\end{array}$ & $\begin{array}{c}\text { Ductility } \\
\text { Factor } \mu=\Delta_{\mathrm{u}} \\
/ \Delta_{\mathrm{y}}\end{array}$ & $\begin{array}{c}\text { Energy } \\
\text { Absorption } \\
(\mathrm{Nm})\end{array}$ \\
\hline \multirow{12}{*}{$9 \times 9 \times 0.75$} & 50 & \multirow{4}{*}{ M25 } & 180 & 9.90 & 9.79 & 1.011 & 891 \\
\hline & 80 & & 180 & 8.72 & 8.65 & 1.008 & 785 \\
\hline & 100 & & 180 & 8.52 & 8.46 & 1.007 & 767 \\
\hline & 125 & & 180 & 4.29 & 4.26 & 1.006 & 386 \\
\hline & 50 & \multirow{4}{*}{ M30 } & 180 & 9.22 & 9.09 & 1.014 & 830 \\
\hline & 80 & & 180 & 8.56 & 8.48 & 1.009 & 770 \\
\hline & 100 & & 180 & 8.30 & 8.24 & 1.007 & 747 \\
\hline & 125 & & 180 & 4.17 & 4.15 & 1.004 & 375 \\
\hline & 50 & \multirow{4}{*}{ M35 } & 180 & 9.12 & 9.00 & 1.013 & 821 \\
\hline & 80 & & 180 & 8.45 & 8.35 & 1.012 & 761 \\
\hline & 100 & & 180 & 8.21 & 8.12 & 1.011 & 740 \\
\hline & 125 & & 180 & 4.01 & 3.98 & 1.008 & 361 \\
\hline
\end{tabular}


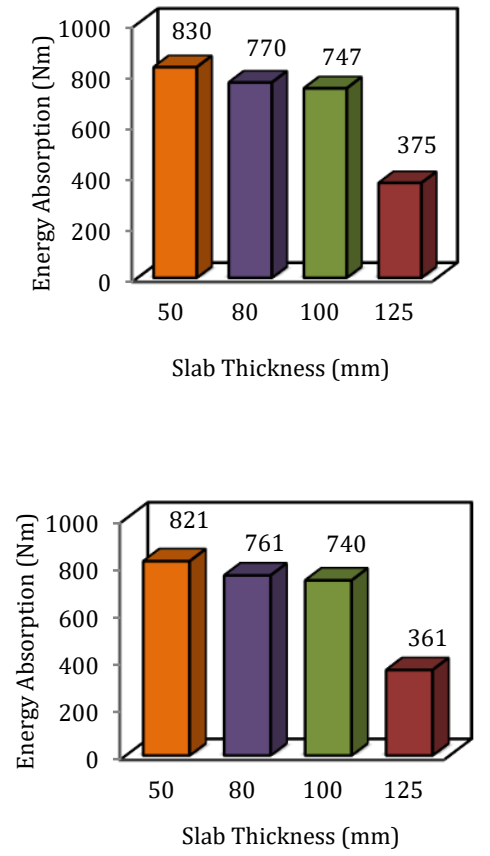

Fig. 5: Comparison of energy absorption capacity of composite space truss (M25, M30 and M35)

Stiffness is defined as the ability to resists deflection. Stiffness value is calculated as the ratio of the load increment to the corresponding deflection at the centre of the composite space truss. The variations in the stiffness of two truss $4 \mathrm{~m} \times 4 \mathrm{~m}$ and $9 \mathrm{~m} \times 9 \mathrm{~m}$ with the slab thickness of $50 \mathrm{~mm}, 80 \mathrm{~mm}$, $100 \mathrm{~mm}$ and $125 \mathrm{~mm}$ are shown in Figs. 6 and 7. Decrease in the stiffness with the increase in the load is observed and the rate of decrease is more in the initial load range. Behaviour of composite space truss with $125 \mathrm{~mm}$ slab thickness which behaved in a stiff manner over the load range is shown in Figs. 6 and 7. In general, the stiffness of the composite space truss is much higher than that of non-composite space truss.

\section{Conclusion}

The study on the analytical behaviour using ABAQUS was carried out employing published experimental results of Elsheikh (1998) model of size $4 \mathrm{~m} \mathrm{x} 4 \mathrm{~m}$ and Mezzina et al. (1975) model of size $9 \mathrm{~m} \times 9 \mathrm{~m}$ for composite space truss.

The influence of various parameters like thickness of slab, module size and concrete strength were also studied. From the analytical study following conclusion were arrived. The increase in the thickness of concrete slab over the space truss is having relatively high stiffness. The slab of $125 \mathrm{~mm}$ is five times stiffer than the $50 \mathrm{~mm}$ slab. The increase in the slab thickness of the composite space truss enhances energy absorption capacity. The ductility factor does not significantly change when the size, slab thickness and grade of concrete is changed.

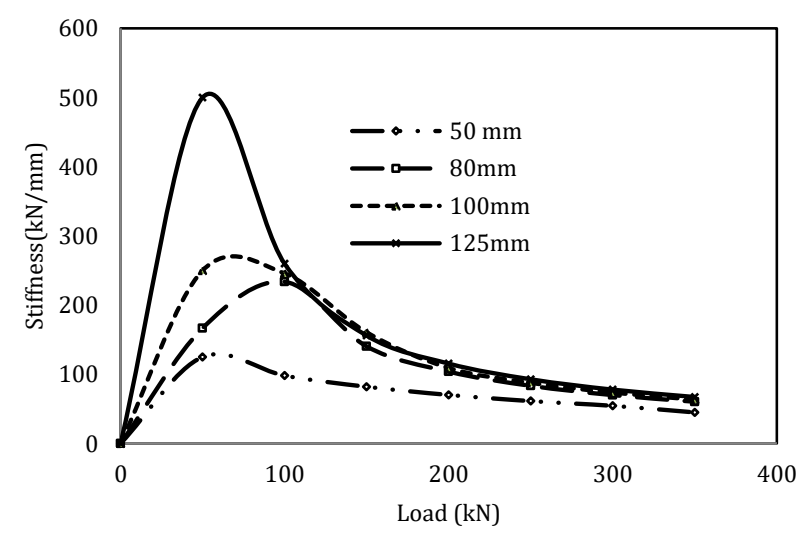

Fig. 6: Load - Stiffness behaviour of composite space truss $(4 \mathrm{~m} \times 4 \mathrm{~m})$ 


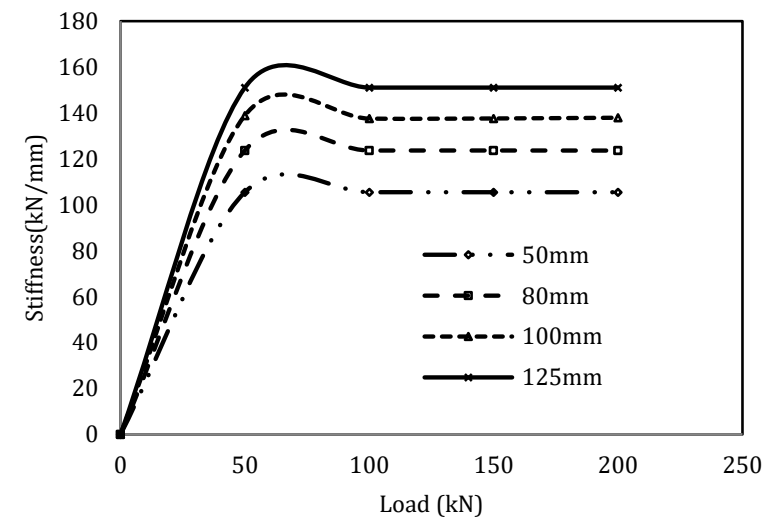

Fig. 7: Load - Stiffness behaviour of composite space truss $(9 \mathrm{~m} \times 9 \mathrm{~m})$

\section{Acknowledgment}

The author wishes to thank the Management of SSN College of Engineering for providing the necessary facility to carry out the present work.

\section{References}

Elsheikh A (1998). Optimum design of space trusses. Journal of International Association for Shell and Spatial Structures, 39(3): 159-168.

Elsheikh A and McConnel RE (1993). Experimental study of behaviour of composite space trusses. Journal of Structural Engineering, ASCE, 119(3): 747-766.

Lakshmikandhan KN, Senthil R, Arul Jayachandran S, Sivakumar P, and Ravichandran R (2010). Parametric studies on the behaviourof steel and composite space structures. International Journal of Space Structures, 25(3): 169-183.

Mezzina M, Prete G, and Tosto A (1975). Automatic and experimental analysis for a model of space grid in elastoplastic behaviour. In the $2^{\text {nd }}$ International Conference on Space Structures, University of Surrey, Guilford, UK.

Sangeetha P and Senthil R (2017). A study on ultimate behaviour of composite space trusses. KSCE Journal of Civil Engineering, 21(3): 950-954. 